\title{
Rural livelihoods and climate variability in Ningxia, Northwest China
}

\author{
Yue Li • D. Conway • Yanjuan Wu • Qingzhu Gao • S. Rothausen • Wei Xiong • \\ Hui Ju $\cdot$ Erda Lin
}

Received: 9 August 2012 / Accepted: 6 April 2013 /Published online: 1 May 2013

(C) The Author(s) 2013. This article is published with open access at Springerlink.com

\begin{abstract}
This study addresses the role of climate variability in the livelihoods of agricultural communities in Ningxia, Northwest China. Data sources comprise meteorological observations and official reports, complemented by questionnaires and focus group discussions designed around a livelihoods framework. Sample villages were located in three different agricultural systems: irrigated, mixed irrigated/grazing, and rainfed. Much of Ningxia is perennially dry and this is a significant limiting factor to agricultural production in the region, exacerbated by drought and buffered by irrigation mainly supplied from the Yellow River. Climate observations show stable temperatures from the 1950 s to the 1980 s followed by a positive trend $\left(0.38^{\circ} \mathrm{C} /\right.$ decade $\left.1961-2010\right)$. Precipitation shows very modest trends and low decadal variability. Recent climate variability, particularly a drought from 2004-2006, was perceived to have had a significant effect on agricultural production and access to water, but it was not the only challenge respondents had faced. Susceptibility to drought was higher in the mixed irrigated and grazing and rainfed areas, due to farmers' greater exposure to climatic hazards and because a higher proportion of their income originated from farming activities. Respondents were using a wide range of measures to retain and enhance soil moisture and maintain agricultural production. The discussion examines challenges in disentangling the role of climate within rapidly changing livelihood systems.
\end{abstract}

Electronic supplementary material The online version of this article (doi:10.1007/s10584-013-0765-9) contains supplementary material, which is available to authorized users.

Y. Li $\cdot$ Q. Gao $\cdot$ W. Xiong $\cdot$ H. Ju $\cdot$ E. Lin

Institute of Environment and Sustainable Development in Agriculture, Chinese Academy of Agricultural Sciences, 12 Zhongguancun South Street, Beijing 100081, China

D. Conway $(\bowtie) \cdot$ S. Rothausen

School of International Development/Tyndall Centre for Climate Change Research, University of East Anglia, Norwich NR4 7TJ, UK

e-mail: d.conway@uea.ac.uk

Y. Wu

Inner Mongolia Weather Bureau, No.49, Hailaer Street, Hohhut, Inner Mongolia 010051, China 


\section{Introduction}

This study contributes to China's growing engagement with adaptation and forms part of a wider vulnerability assessment to contribute to the development of an adaptation strategy for the agricultural sector in Ningxia province of Northwest China (Ju et al. 2008). Ningxia was chosen as the focus of the project because it possesses three quite different agricultural production systems with specific vulnerabilities and climate risks and because poverty levels are higher than the national average. Few studies until now have considered in detail the role of climate in rural livelihoods in China. Liu et al. (2008) investigated farmers' response to water scarcity in Shandong Province, where, in spite of successive years of low flows in the Yellow River, water-saving agricultural practices were not adopted due to agricultural policies and low cost of water. Hageback et al. (2005) found that government policies and reforms had stronger influence on livelihood changes than climate variability in Danangou watershed, Loess Plateau in China. This is also the case outside China, where adaptation to climate variability or trends is context specific and responses often relate more to changes in policies or the socio-economic situation (Mertz et al. 2009).

Morton (2007) emphasises the need for conceptual frameworks to capture complexity by integrating multiple stressors on livelihoods, considering spatial and temporal variability and examining different types of climate change impacts. Livelihoods studies can provide such a framework with optional levels of detail depending on purpose and practical considerations among other things. In this study a livelihood is taken to be the financial means whereby an individual lives, comprised of capacity, assets, and activities (Chambers and Conway 1992). Assets are crucial, and they are often categorised in the form of natural capital, financial capital, material capital, human capital, or social capital (Ellis 2000). Ideally a livelihoods approach would combine all the resources people are using and their activities to live, however, this is not always possible. Multidisciplinary studies of livelihoods tend to focus more on vulnerability and poverty (Bebbington 1999), often including other related topics such as land, forest, ecology and economy (Sunderlin et al. 2005). Few livelihoods studies consider explicitly the relationship with climate, although as livelihood frameworks incorporate shocks such as drought, they may feature an implicit treatment of climate.

This study aims to describe recent climate variability and characterise its role in the livelihoods of farmers in three contrasting agricultural systems. The analysis is set within a wider context of rapidly evolving livelihood systems as China undergoes economic transition, including income diversification (Wang et al. 2010), migration (Peng 2011), greater access to agricultural technology, crop choices and management techniques, and policy changes such as the programme of subsidies to take marginal land out of production ( $\mathrm{Li}$ et al. 2011a, b; Wang et al. 2011). The methodology combines analysis of climate and economic data, an extensive questionnaire survey, focus group discussions and expert interviews. The paper is organised as follows. First we describe the study area and methods, then analyse recent climate variability and evidence of its economic impacts. The results of the livelihoods survey are presented and responses to climate variability examined. Finally, we explore some challenges to this type of analysis and discuss the relevance of the study to the design and implementation of programmes for adaptation to future climate change.

\section{Study area and research approach}

\subsection{Ningxia Autonomous Hui Region}

Located in northwest China (Fig. 1), Ningxia Hui Autonomous Region is one of the five autonomous regions in China and lies in the upper reaches of the Yellow River with an area of 

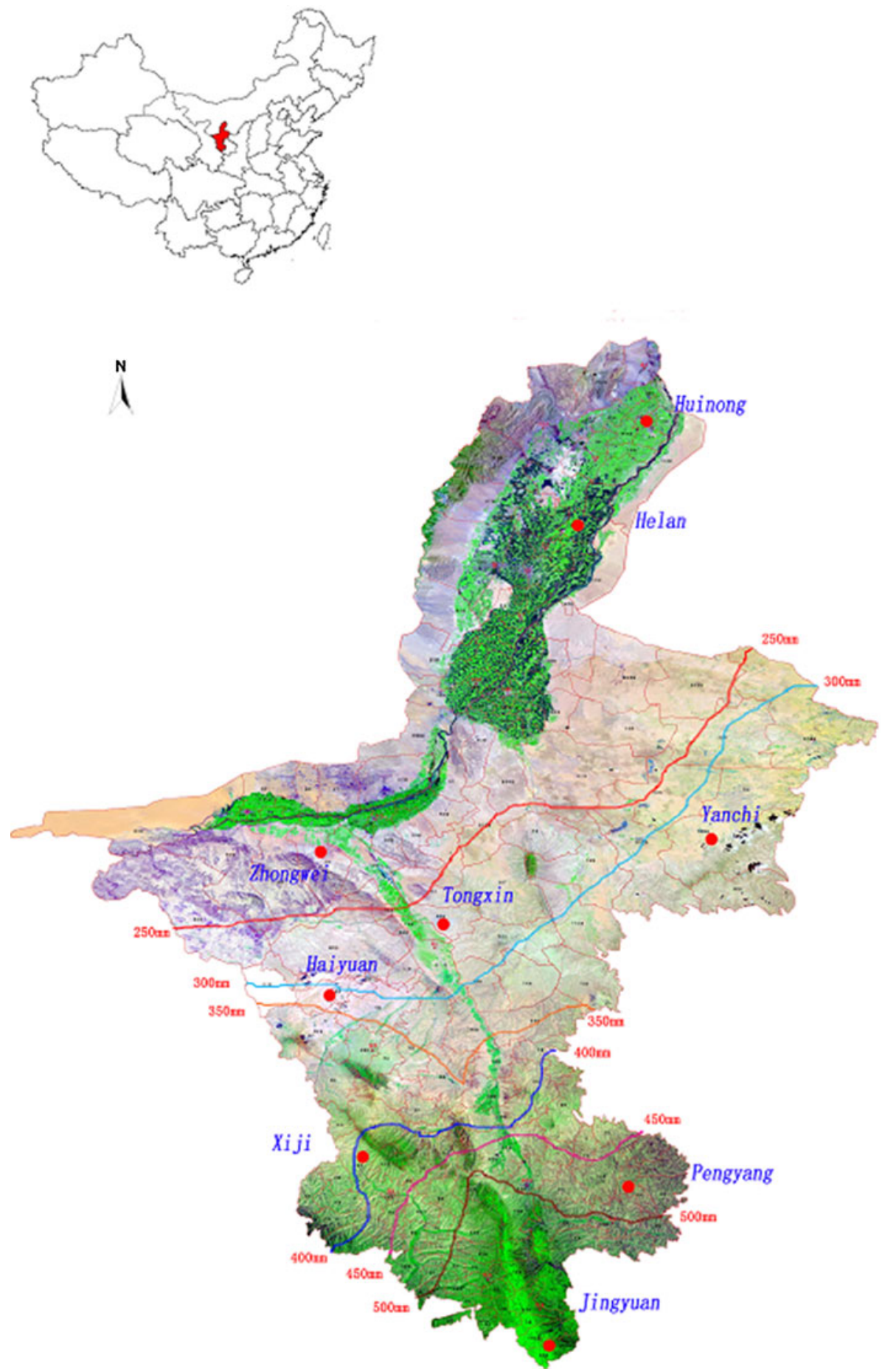

Fig. 1 Location of Ningxia in China, location of study survey towns and villages and isohyets (mean annual precipitation, $50 \mathrm{~mm}$ intervals) 
$66,000 \mathrm{~km}^{2}$. Ningxia was chosen as the focus of the project because it possesses three different agricultural production systems with contrasting exposures and sensitivities to climate. In addition, poverty levels are higher than the national average (Zheng 2007) and the role of agriculture remains important in the economy and as a source of employment throughout the region. Ningxia is largely arid and semi-arid, narrow from east to west and long from south to north and experiences many different extreme weather events. The region experiences very high sunshine duration and solar radiation, hot summers and cold winters, high potential evaporation rates and highly uneven distribution of water resources. Per capita water resources are roughly one tenth of the national average with most of the water derived from the Yellow River through a basin level allocation mechanism.

Time series of annual temperature during 1961-2010 for the three areas are shown in Fig. 2 left panel. Between 1961 and 2010, mean annual temperature ranged from 6.5 to $9.6{ }^{\circ} \mathrm{C}$. Figure 2 right panel shows annual precipitation for the same period. Precipitation between May and September accounted for $81 \%$ of the annual total with only 2 months, July and August, recording above $50 \mathrm{~mm}$. The three main geographical areas, each with quite distinct agricultural production systems, are as follows:

1. Southern mountainous area: rainfed cultivation in the region's most humid area, with a range of average annual precipitation from $324 \mathrm{~mm}$ to $740 \mathrm{~mm}$. Potato is the main crop and cattle, sheep, pigs and chickens the main livestock;

2. Central arid area: a mix of irrigation with some rainfed and extensive grazing (mixed irrigated and grazing). Average annual precipitation ranges from $173 \mathrm{~mm}$ to $559 \mathrm{~mm}$. The dry conditions only allow corn, spring wheat, potato, and some cattle and sheep husbandry;

3. The northern irrigation area: arid with primarily irrigation using water diverted from the Yellow River. Annual precipitation ranges from $78 \mathrm{~mm}$ to $309 \mathrm{~mm}$. Intercropping is the major planting system. The main crops are corn, spring wheat, paddy rice and potato. Cattle, sheep, pigs and chickens are the main livestock.

\subsection{Data and methods}

Monthly precipitation and maximum and minimum temperature observations from 22 stations in Ningxia were obtained from the Ningxia Meteorological Archives, covering the period 1961 to 2010. Reports and discussions with officials from Ningxia's Meteorological Bureau were used to provide an overview of the economic effects of extreme weather events. The sampling and livelihoods survey design were broadly structured around a livelihoods framework (Scoones 1998). Nine villages were selected, three from each agro-ecosystem, guided by discussions with local people and officials bearing in mind distance to urban areas, and accessibility to resources and other services, the specific crops farmers were dependent on, and levels of wealth. At least 30 households were selected in a random manner from each village, with the distribution of 10 high income households, 10 medium income households, and 10 low income households. Each village sits within a county, with the selected counties being Huinong, Helan and Zhongwei located in the northern irrigation area, Tongxin, Yanchi and Haiyuan in the central arid area, and Jingyuan, Pengyang and Xiji in the southern mountainous area (locations in Fig. 1).

The questionnaire survey collected the following information: background about respondents, farming (and other) activities, experiences of recent climate variability and associated impacts, response measures and farmers' expectations of existing and potential government support. Detailed quantitative data on income and expenditure were not collected. The survey and associated data entry were completed between March and November 2007. 
289 households were interviewed in nine administrative villages, 95 households in the northern irrigation area, 101 households in the central arid area and 93 households in the southern mountainous area. Other information was obtained from informal and semistructured interviews and focus group discussions with selected residents in the target areas (following for example, Slocum 2003). At the provincial level, informal and semi-structured interviews and one focus group discussion was conducted with officials from departments of agriculture, water resources and poverty relief and scientists from Ningxia's provincial universities and research institutes. In each county, one informal and semi-structured interview and focus group discussion was conducted with the attendance of local officials mainly from departments of agriculture and water resources and extension service staff. In each village, one focus group discussion was held with the attendance of around 10 people, including village leaders and famers. For the informal and semi-structured interviews and focus group discussions the main topics discussed covered; perceptions of recent climate variability, their effects on crops and response measures of farmers and the state.

\section{Climate variability and extreme events in Ningxia}

\subsection{Temperature and precipitation variability in Ningxia, 1961-2010}

There have been consistent warming trends in annual and seasonal temperatures across the whole region which are most pronounced from the late 1980s onwards (Fig. 2 left panel, Supplementary table S1). The trends in Ningxia are similar to those in nearby provinces of China (EBSNCCA 2011). The rate of annual temperature increase for the whole region was $0.38^{\circ} \mathrm{C} /$ decade during 1961 to 2010 . During more recent periods warming was more rapid, particularly in the northern irrigation area $\left(0.60^{\circ} \mathrm{C} /\right.$ decade during 1981 to 2010 and 1991 to $2010)$ and the southern mountainous area $\left(0.60^{\circ} \mathrm{C} /\right.$ decade and $0.67^{\circ} \mathrm{C} /$ decade, during 1981 to 2010 and 1991 to 2010 , respectively). Seasonal trends in temperature were similar in the three areas with the greatest warming during the most recent period. During 1961-2010 temperatures in winter months (December, January, and February) showed the most warming (Supplementary table S1).

There was a modest decreasing trend in annual precipitation in all three areas during 19612010 (Fig. 2 right panel), however, this trend is influenced by the two very wet years near the beginning of the record (1961 and 1964). With both years removed there is no overall trend. The coefficient of variation for the whole region was $18 \%$ and for the northern, central and southern
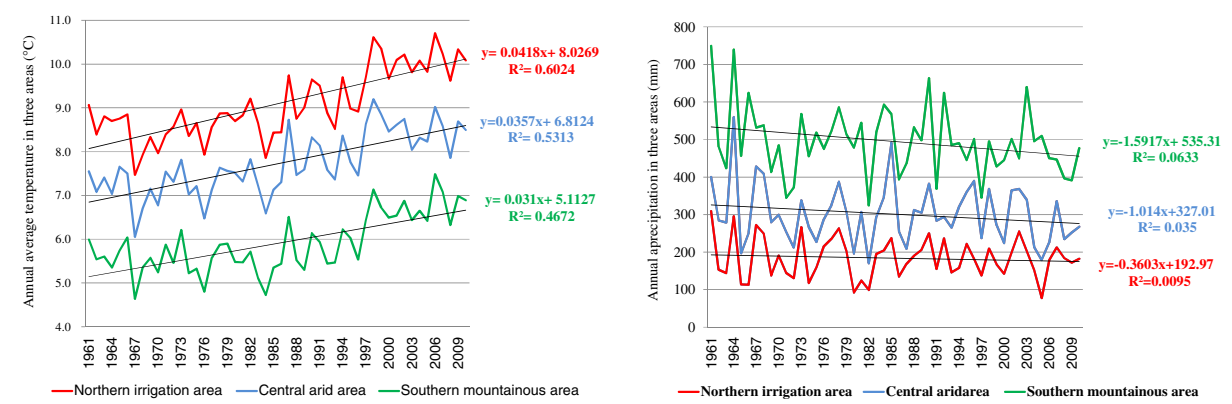

Fig. 2 Annual temperature and precipitation series, non-weighted average for the three areas in Ningxia, 1961-2010 (22 stations) 
areas it was $25 \%, 20 \%$ and $14 \%$, respectively. Decadal variability has been fairly low with slightly drier conditions during the 1970s and late 1980s whereas the early 1990s were slightly wetter. There has been a small decrease in precipitation from the mid-1990s to the present.

Seasonal precipitation patterns are more complex (Supplementary table S2). Over the full period modest decreases in precipitation have occurred in all three areas, most pronounced during the summer (JJA) and autumn (SON). In contrast, winter (DJF) shows a slight increasing trend. From 1981 to 2010 the largest decrease in precipitation occurred in spring (MAM) and summer, particularly in the central and southern areas. This is a critical time for crop sowing and development. The most recent period (1991 to 2010) has seen some quite marked trends, with decreases in summer of 11, 38 and $43 \mathrm{~mm} /$ decade and spring of 3,12 and $2 \mathrm{~mm} /$ decade in the northern, central and southern areas, respectively.

\subsection{Economic and agricultural impacts of climate variability in Ningxia}

Ningxia has numerous meteorological hazards, including drought, floods, sandstorms, hot winds, hail, frost, gales, torrential rain and high and low temperature stress. Official statistics from Ningxia's Meteorological Bureau on agricultural disasters show that during the period 1949 to 2000 , on average $23 \%$ of the region's arable land (equivalent to 480,000 ha) experienced yield losses of $10 \%-30 \%$ and $17 \%$ of the area yield losses greater than $30 \%$. Drought was the most frequent meteorological hazard and its damaging effects on cropland have increased from 1984 to 2007. In addition to drought, hail and frost caused the second and third largest yield losses greater than $30 \%$. Of the hazards that affect arable land (i.e. reducing yields), drought, hail, and frost accounted for $55 \%, 21 \%$ and $10 \%$, respectively, by area.

The average annual direct economic loss in the agricultural sector due to meteorological hazards was roughly RMB 0.658 billion and has increased in recent years (Supplementary Figure S1, left panel). The annual average grain loss was roughly 462,000 t from 1994 to 2004 (Supplementary Figure S1 right panel). Both indicators show a sharp rise after 2003 and 2000 such that the direct economic loss increased to RMB 0.905 billion and grain loss increased to $690,000 \mathrm{t}$, respectively, for the period 2000 to 2004 . ${ }^{1}$

An intense prolonged drought occurred between 2004 and 2006 across much of central and northern Ningxia. In the northern irrigation and central arid areas annual average precipitation during 2004 to 2006 was $26 \%$ and $32 \%$ below average (1961 to 2006), respectively. 2005 was the driest year, with precipitation $58 \%$ and $41 \%$ below average, respectively, for the Northern irrigation area of Ningxia it was the driest year on record and for the central arid area second driest on record (Fig. 2 right panel). The drought affected the southern mountainous area much less; in 2004 and 2005 precipitation was close to average (495 mm) and in 2006 about $10 \%$ below average.

During the drought crop planting in summer and autumn was disrupted, for example, according to the Civil Affairs Department in the central arid area 421,000 ha were affected (leading to yield reductions of $10 \%$ to $30 \%$ ) and 289,000 ha of which experienced yield reductions $>30 \%$. Approximately 720,000 people were affected during the event and 463,000 experienced problems obtaining drinking water. Drought impacted the quality and yield of grazing grassland which in turn affected the number and quality of livestock. The annual average direct economic loss caused by the drought was 1.27 billion RMB (In 2006 $\mathrm{US} \$ 1=6.83 \sim 8.07 \mathrm{RMB}$; Li et al. 2006). In the summer of 2006 the continued severe drought affected 184 villages in 26 townships across 12 counties in the central area. This included reduced yields for some 547,000 ha of arable land. Drought was main causal factor

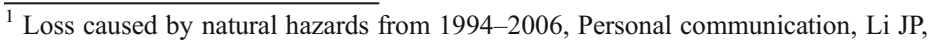


triggering poverty (defined as annual income <RMB 625) in Ningxia from 1994 to 2004 (Supplementary Figure S2).

\section{Recent climate variability and rural livelihoods}

The following sections present the results of the questionnaire survey, semi-structured interviews and focus group discussions. The main themes are ordered as follows: general overview of the communities and their livelihood income sources, experiences of recent climate variability, effects on livelihoods and response measures.

The Han ethnic group was predominant in the northern irrigation and southern mountainous areas, and the Hui minority predominant in the central arid area. The percentage of income from different sources in the three different areas (Fig. 3) shows respondents in the northern irrigation area received income mainly from growing cereals $(40 \%)$, working in urban areas $(23 \%)$, or from raising domestic animals $(13 \%)$, with limited income from growing cash crops and local businesses. In the central arid area income derived mainly from working in urban areas $(31 \%)$, raising domestic animals $(23 \%)$, government subsidies (16\% of total income) and growing grain crops (17\%). One exception was Tongxin where growing grain crops was more important as water is available from the Yellow River. In the southern mountainous area income mainly derived from working in urban areas (27\%), government subsidies $(23 \%)$ and growing cereals and cash crops $(25 \%)$.

Key factors that were felt to affect farmers' income (Supplementary Figure S3) included hazards (mainly meteorological ones) and diseases (crop and livestock). Production expenditure, resources, and agricultural policies were the other factors most frequently mentioned. The impact of production expenditure on income was felt most strongly in the northern irrigation area, which is associated with more intensive farming and livestock rearing.

\subsection{Perceptions of recent climate variability and the most serious hazards}

In all three areas most respondents believed precipitation was lower than a decade before and felt that they had experienced more droughts in the last decade. Drought was identified most frequently as the main meteorological hazard in all three areas (Supplementary Figure S4). In the central arid and southern mountainous areas, $99 \%$ and $100 \%$ of respondents believed there had been some increases in drought frequency, respectively, with similar proportions

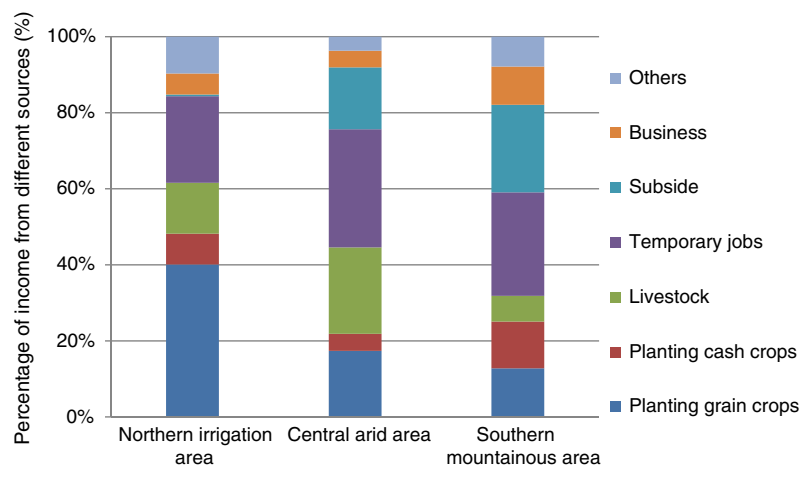

Fig. 3 Percentage income from different sources across the three areas 
ranking drought as the most serious hazard. In the northern irrigation area interviews and focus group discussions confirmed that respondents felt climate had become drier but that had no significant effects on their crop yields. In some cases, net income had declined mainly because more irrigation was required but also due to greater expenditure on pesticides and the warmer climate resulting in more frequent outbreaks of pests. $87 \%$ of respondents reported that drought was more frequent and $83 \%$ felt that drought was the most important hazard in the northern area.

The precipitation series (Fig. 2 right panel) show that it was mainly the 3 years prior to and during the survey that were much drier than usual. The annual precipitation in these years was $26 \%, 32 \%$ and $3 \%$ lower than that in the period of 1961 to 2006 in the northern, central, and southern areas, respectively. This is likely to have influenced respondent's perceptions of higher frequency of drought. The records since 2006 show a recovery in two of the three areas suggesting the droughts were fluctuations, not part of a long-term drying trend.

Frost was also identified as a problem and respondents noted that increased exposure to this hazard had been partly caused by their adaptations to local warming by expanding their planting area of winter wheat to higher elevations. In the central arid area, sand storms, high temperatures, frost and frozen ground were identified as problems but considered to be less important than drought.

Cross-referencing the rankings of hazard importance with climate data and the results from the focus group discussions highlighted several examples of particular hazards and these are summarised in Table 1. Interviews and focus group discussions in the central arid area confirmed that drought was the main factor to affect farmers' incomes. Farmers mainly dependent on agricultural activities were more affected and when serious drought occurred they lost all income from planting crops and breeding livestock. In addition, grain price increased during drought so that expenditure on grain purchase increased substantially. Drought therefore resulted in multiple impacts on farmers' incomes due to combined effects from reduced grain production and livestock sales, and greater expenditure on cereal foodstuffs and drinking water which became more expensive due to scarcity (see Section 4.2). In the southern mountainous area discussions generally found that farmers who relied solely on agricultural activities were most vulnerable to meteorological hazards which in some cases could reduce farmers' incomes by up to $50 \%-60 \%$.

\subsection{Impacts on farmers' livelihoods and agricultural production}

The effects of the worst drought in living memory differed across the three agricultural systems. Overall, respondents in the northern irrigation area experienced least impact. Nevertheless, recent climate variability and particularly the major drought, had clearly touched many aspects of farmers' livelihoods throughout the region.

Access to water for drinking and irrigation The northern irrigation area is supplied from the Yellow River and farmers generally had access to both tap water and well water and did not see this as an important issue (Supplementary Table S3). However, of the three surveyed villages from $40 \%$ to $62 \%$ of the respondents felt it had become more difficult to obtain water for irrigation as a result of reduced precipitation, droughts, rationing of Yellow River water and increased water tariffs.

In the central arid area $94 \%$ of respondents felt it had become increasingly difficult to obtain drinking water. In Tongxin and Yanchi counties drinking water was secure for most people and animals, though in some localities people had to buy water during drought. Farmers 


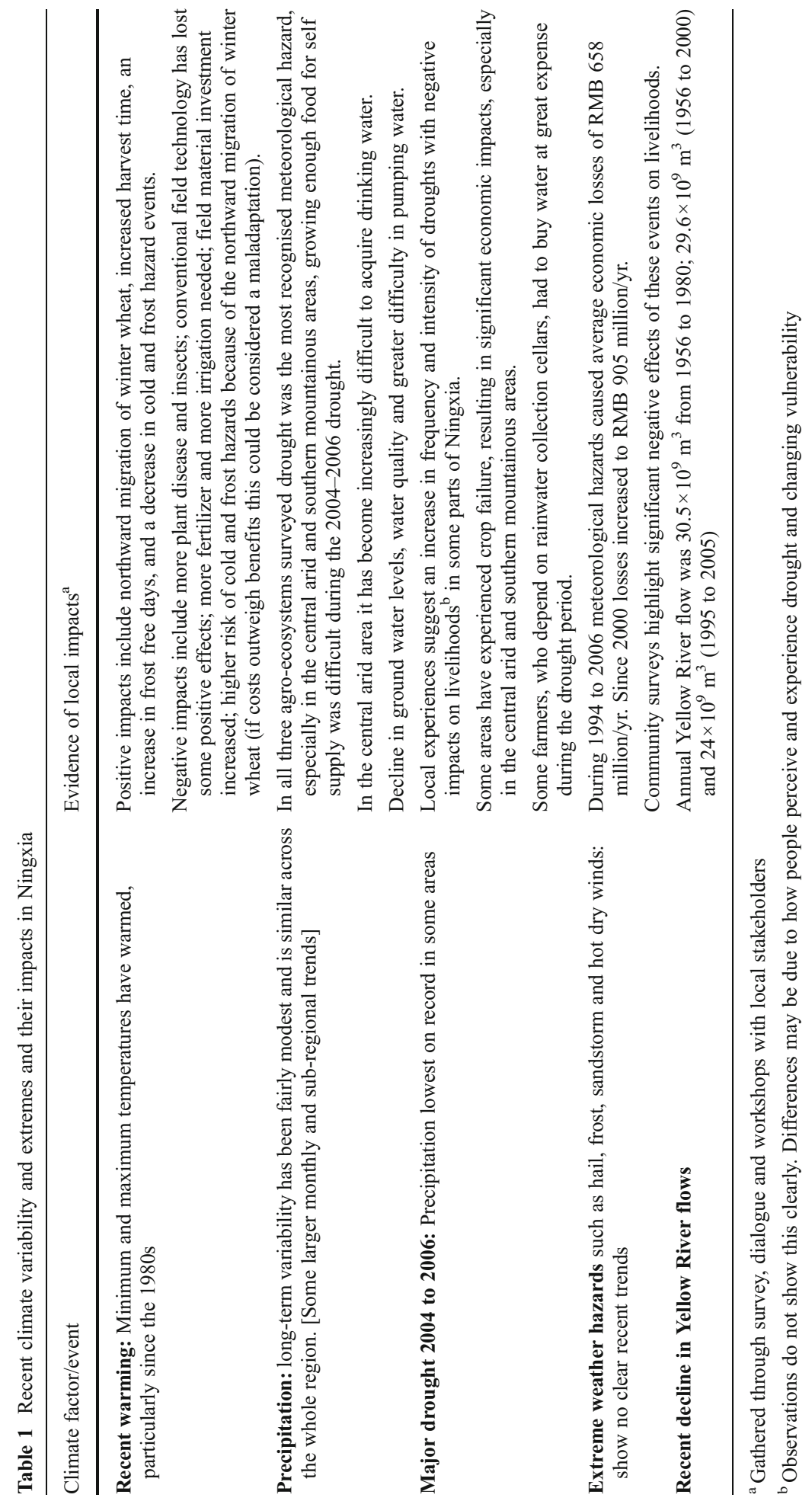


who were reliant on rainwater collection cellars in Haiyuan had to buy water during dry periods as their storage was depleted, in some cases from sources that were $80 \mathrm{~km}$ from their village. Some local people with tractors transported water in and sold it to local households. Interviews and focus group discussions showed that prior to 2002 farmers' water resources were mainly from rain water harvesting but since then farmers had to increasingly buy water due, in some degree, to the effects of the drought. The average payment for a two-person household was at least $500 \mathrm{RMB}$. The average net income of households in the surveyed counties in the central and southern areas in 2005 ranged from 1446 RMB in Haiyuan to 2004 RMB in Yanchi (NSB 2006). This suggests that in some cases more than $30 \%$ of farmers' income was spent on drinking water. This was in areas where a considerable proportion of their income came from subsidies through the 'Grain for Green' Programme ${ }^{2}$ and temporary paid work.

In the southern mountainous area, Jingyuan used groundwater for humans and livestock but droughts had led to lower water levels, with less groundwater available to farmers, although basic water needs were satisfied. Xiji had more available water, however, it was still common for farmers to have to buy it or augment supply with groundwater.

Impacts of drought on grain self-sufficiency and grain price Respondents were asked about the effects of the most serious drought on their grain production and what this meant for their own household consumption, with varying results across the region (Supplementary Figure S5). Respondents found it difficult to directly quantify changes in yield or production in absolute terms. Least impact was felt in the northern irrigation area where roughly $90 \%$ of respondents ticked either "having enough food to eat" or "no serious impacts on their agricultural production". All three survey villages in the southern mountainous area had at least $45 \%$ of their respondents who ticked "insufficient food". 10-30\% of the respondents ticked "no yield' and more than $74 \%$ of respondents ticked "serious impacts on their grain production". The perception of drought impact was the most serious in the central arid area. All four response options were fairly evenly selected by respondents in Tongxin (because the village had irrigation where water rationing was more of an issue than drought), whilst $95 \%$ of respondents in Yanchi and Haiyuan selected the worst category. Field investigations in Yanchi and Haiyuan found that reduced precipitation (in Haiyuan this had been for five successive years) had produced major impacts on local grain production. The increased frequency and intensity of droughts had forced farmers out of arable farming and as a result subsidies from the 'Grain for Green' Programme had become a vital income source for most farmers. Around $60 \%$ of respondents in the northern irrigation and southern mountainous areas felt that meteorological hazards could increase grain prices whilst $80 \%$ felt this in the central arid area.

Impacts on production through cropping patterns and sown areas $85 \%$ and $43 \%$ of the respondents in the central arid and southern mountainous areas, respectively, indicated that drought had been a major factor causing change in cropping pattern and sown area during the last decade (Supplementary Figure S6). In the central arid area, weather and climate (decreased precipitation and increased droughts) were indicated to be the main reasons for change, above other factors such as market factors and distribution of irrigation water. Unsurprisingly farmers in all three areas were inclined to choose crops that were adaptive, multi-functional and high yielding with better economic returns, such as corn, potato, Chinese Wolfberry and sunflowers. In the southern mountainous area there were different responses between counties; $60 \%$ of respondents in Xiji had changed their cropping pattern

\footnotetext{
${ }^{2}$ Grain for Green Programme provides subsidies for farmers to convert farmland to forest in areas with slope greater than 25 degree (e.g. Wang et al. 2011)
} 
whereas $60 \%$ in Jingyuan and Pengyang had not. Cropping patterns in Jingyuan and Pengyang had changed because of the influence of the 'Grain for Green' Programme. In Xiji the drought resistance of potato and its high market price were major reasons given by respondents for the increase in planting area.

Respondents also noted changes in sown area for more advantageous crops. The reasons given included recent climate variability, change of market price and policy guidance. For example, in Haiyuan the local government had introduced watermelon in response to the drier conditions. Covering the ground surrounding the watermelon with small stones enhances moisture retention, improving drought resistance. This crop also had very strong market potential. Insights from the focus group discussions showed that the sown area for maize planting contracted because soil moisture was insufficient for germination. This is supported in the Ningxia Statistical Yearbook (NSB 2006) which shows a $5 \%$ decrease in sown area for maize in 2005 compared to 2004 across the whole region. In our surveyed counties in the central and southern areas the sown area for maize decreased even more, ranging from $14 \%$ to $46 \%$, compared to 2004. When there is insufficient soil moisture farmers plant potato instead of maize or wheat. Therefore the sown area for potato increased during the major drought and in other less extreme dry years (NBSC, 1999, 2000, 2005, and 2006). The sown area for winter wheat has increased associated with a northward expansion of the sown area and this has led to higher incidence of frost injury.

Agricultural measures to cope with Ningxia's dry and variable climate The perennially dry climate and limited soil moisture availability defines the nature and challenges of agricultural production in Ningxia. These challenges are greatly exacerbated by periodic drought. Naturally, farmers adopt a wide range of measures to retain and enhance soil moisture. In addition, state services support many new agricultural technologies and methods to sustain and increase productivity in this difficult agricultural environment.

Harrowing to break up clods and lumps of soil, film mulching and sand cover are most frequently used by farmers to retain soil moisture. Most popular was harrowing which was used by farmers in all the sites investigated, particularly in the northern irrigation and southern mountainous areas. This could increase yields by around $40 \%$ according to the respondents and had a relatively low capital cost. Other measures showed large differences in use by area, for example, film mulching was widely applied in Huinong to support dehydrated vegetable production and in Pengyang and Jingyuan (southern mountainous area) it increased yield by $45 \%-50 \%$. Mulching with small stones was only applied in Haiyuan where it had become an effective measure for coping with droughts, however, it was labour intensive and costly (around $6000 \mathrm{RMB} / \mathrm{ha}$ ) making it only applicable for high value crops such as watermelon.

Rainwater collection measures were used extensively across the central and southern mountainous areas in different ways. Discussions in the field found that the central arid area had a tradition of using water collected in cellars for farming and domestic purposes. Each household generally had one or two water cellars. Cellar construction was partially financed by local government in the form of cement and bricks, with a $50 \%$ proprietary payment by local farmers. The cost of one cellar was around $1350 \mathrm{RMB}$ in the central arid area and $1500 \mathrm{RMB}$ in the southern mountainous area, in Pengyang farmers used the catchment area $^{3}$ and water cellars. The government also provided similar levels of support in this area.

\footnotetext{
${ }^{3}$ Man-made open-air surfaces that are designed especially for rainwater harvesting. There are various materials that can be used to reduce permeability, such as gravel-covered plastic sheeting, concrete, asphalt and fibreglass. Compacted earth is commonly used and is also the cheapest option.
} 
Furrow irrigation was the most popular water saving technology in the northern irrigation area. Survey results showed that only Huinong and Helan had adopted water saving measures. Government extension agents had found it difficult to disseminate the idea of a small plot area to improve water use efficiency because of its labour intensity and unsuitability for mechanical plowing. Irrigation technologies such as sprinklers were not suitable in the area due to the high sand content of the water diverted from the Yellow River.

\section{Discussion and conclusions}

This study aimed to explore effects of recent climate variability on aspects of livelihoods in three contrasting agricultural systems in Ningxia. This involved analysis of climate and economic data and a livelihoods survey in nine villages. However, without a very detailed questionnaire to capture all aspects of assets and income it is difficult to quantify fully climate effects and therefore we exercise caution in interpreting our results. For example, questions about crop choice may conflate climate consequences with economic reasons that may be more important. In addition, livelihoods are complex and dynamic, being made up of numerous activities and climate is just one of many influences on behaviour and outcomes.

The review of meteorological hazards demonstrates their economic importance. Direct economic losses in the agricultural sector showed a step jump in 2001 from RMB 910 million to RMB 1.27 billion per year. The livelihoods survey and more qualitative consultation showed varying and in some cases considerable effects of climate on agricultural production and activities. The effects of periodic droughts were predominant although warming trends of $0.57{ }^{\circ} \mathrm{C}$ since 1981 had influenced management decisions such as crop selection and expansion of sown areas. The effects of climate variability varied across the region, particularly between agricultural production systems. Susceptibility to drought was higher in the central and southern areas due to farmers' greater exposure (reliance on rainfed agriculture) and because a higher proportion of their income originated from farming activities.

Interpreting the implications of future climate change within rapidly evolving livelihood systems is a challenging exercise. For much of rural China over the next 10-20 years political and socioeconomic drivers are likely to exert the greatest influence on rural livelihood trajectories, although in specific locations periodic extreme events will have significant consequences. Off-farm income generation was important in Ningxia, with over $50 \%$ of respondents engaged in such activities. Migration, although not captured in our survey, is deeply important in Ningxia and other parts of northwest China, government programmes for resettlement (also called ecological migration) from very remote or marginal locations to more productive ones are a widespread phenomenon. For example, most residents of Yanghetaozi village in Tongxin county were migrants whose forefathers lived in a village called 'crying for water' located deep in the mountains. Diverted water from the Yellow River has allowed resettlement in Hongsipu where development of 27,000 ha of irrigated farmland has supported in-migration of around 200,000 farmers.

The extent to which understanding of current livelihood contexts can provide insights for adaptation to future climate change is complicated by their rapidly changing socio-economic contexts and uncertainty about how future climate change and its consequences will be manifest. $\mathrm{Li}$ et al. ( $\mathrm{Li}$ et al. 2011a) present multi-model climate projections for part of northern China including Ningxia project annual warming for the $2020 \mathrm{~s}$ of $1.3{ }^{\circ} \mathrm{C}$ (A2 emissions) and $1.2{ }^{\circ} \mathrm{C}(\mathrm{B} 1)$. Annual precipitation is projected to increase by $3 \%$ (A2) and $+7 \%$ (B2) by the $2020 \mathrm{~s}$ and $+9 \%$ and $+8 \%$ by the 2050 s, respectively. Average results such as these obscure considerable range in outcomes and say nothing about the likelihood of changes in frequency and intensity of drought across the region; the concern that was uppermost for our 
respondents in Ningxia. Notwithstanding this, understanding of community-level experiences and support mechanisms from the state is essential to guide adaptation strategies. Our results show how farmers in Ningxia use a wide range of measures to maintain or increase agricultural production in the harsh environment. When asked about the constraints they faced in adapting to the effects of future climate change, respondents most often cited lack of money alongside water availability (for irrigation) and inadequate infrastructure. They felt that government could play a greater role for example through financial support for the construction of infrastructure and investment for agricultural activities. Adaptation considerations clearly need to be set in the context of existing rural development programmes in Ningxia; local experiences and expertise are essential to inform programme design.

Acknowledgments This study was made possible by funding from the UK DEFRA (Department for Environment, Food, and Rural Affairs) and DFID (Department for International Development) of the UK (Grant No. 14703821).

Open Access This article is distributed under the terms of the Creative Commons Attribution License which permits any use, distribution, and reproduction in any medium, provided the original author(s) and the source are credited.

\section{References}

Bebbington A (1999) Capitals and capabilities: a framework for analysing peasant viability. Rural Livelihoods and Poverty World Development 27(12):2021-2044

Chambers R, Conway G (1992) Sustainable rural livelihoods: Practical concepts for the 21st century. IDS Discussion Paper 296. Institute of Development Studies, Brighton

EBSNCCA (Editorial Board of Second National Climate Change Assessment) (2011) Second National Climate Change Assessment Report. Science Press, Beijing. Page 41-42

Ellis F (2000) Rural livelihoods and diversity in developing countries. Oxford University Press, Oxford

Hageback J, Sundberg J, Ostwald M, Chen D, Yun X, Knutsson P (2005) Climate variability and land-use change in Danangou watershed, China-Examples of small-scale farmers' adaptation. Climatic Change 72:189-212

Ju H, Conway D, Li Y, Harvey A, Erda L, Calsamiglia-Mendlewicz S (2008) Adaptation framework and strategy part 3: An adaptation strategy for agriculture in Ningxia. Northwest China. AEA Group, UK, $11 \mathrm{pp}$

Li Y, Ju H, Conway D, Preston F, Xiong W, Lin ED, Zhang JS, Wang TM, Jia Y, Gao QZ, Shi F (2006) Impact of climate change on chinese agriculture phase ii: Scoping study report for Ningxia. AEA Group, Oxford, $79 \mathrm{pp}$

Li Y, Conway D, Xiong W, Gao Q, Wu Y, Wan Y, Li Y, Zhang S (2011a) Effects of climate variability and change on Chinese agriculture: a review. Climate Research 50:83-102. doi:10.3354/cr01038

Li J, Feldman MW, Li S, Daily GC (2011b) Rural household income and inequality under the sloping land conversion program in western China. PNAS 108:7721-7726. doi:10.1073/pnas.1101018108

Liu C, Golding D, Gong G (2008) Farmers' coping response to the low flows in the lower Yellow River: a case study of temporal dimensions of vulnerability. Global Environmental Change 18:543-553

Mertz O, Mbow C, Reenberg A, Diouf A (2009) Farmers' perceptions of climate change and agricultural adaptation strategies in Rural Sahel. Environmental Management 43:804-816

Morton JF (2007) The impact of climate change on smallholder and subsistence agriculture. PNAS 104(50):19680-19685

NBSC (National Bureau of Statistics of China) (1999, 2000, 2005, and 2006) China statistical yearbook. China Statistics Press, Beijing (in Chinese)

Ningxia Statistical Bureau (NSB). Ningxia Statistical Yearbook (2006). China Statistics Press

Peng X (2011) China's demographic history and future challenges. Science 333:581-587

Scoones I (1998) Sustainable rural livelihoods: A framework for analysis. IDS Working Paper 72. Institute for Development Studies, Sussex

Slocum N. (2003) Participatory methods toolkit—A practitioner's manual. www.kbs-frb.be

Sunderlin WD, Angelsen A, Belcher B (2005) Livelihoods, forests, and conservation in developing countries: an overview. World Development 33:1383-1402 
Wang L, Zhang JL, Liu LM (2010) Diversification of rural livelihood strategies and its effect on local landscape restoration in the semiarid hilly area of the loess plateau, China. Land Degradation and Development 21:433-445

Wang C, Yang Y, Zhang Y (2011) Economic development, rural livelihoods, and ecological restoration: evidence from China. Ambio 40:78-87. doi:10.1007/s13280-010-0093-5

Zheng C. D. (2007) Development report of agriculture and rural economy in Western Part of China. In, Economic Development Report in Western Part of China. Social Science Press, Beijing. 2007. pp 39 